\title{
Grabados decorativos europeos y los retablos rococó del siglo XVIII en Trujillo (Perú)
}

\author{
Gauvin Alexander Bailey
}

\section{RESUMEN}

El impacto del rococó ha sido tradicionalmente subestimado en el caso de los retablos del Perú. Aunque los estudiosos reconocen que el rococó se manifiesta en algunos retablos de Lima y Trujillo de finales del siglo XVIII como decoración, se ha hecho poco por investigar cómo este estilo llegó al virreinato. Este artículo identifica unas fuentes impresas francesas y alemanas (de la ciudad de Augsburgo) y considera la manera como los artistas locales las utilizaron. También compara el tratamiento de los adornos rococó y sus formas en Trujillo con la manera en que esas formas son tratados en el Cono Sur (actual Argentina y Chile). Aunque ambas áreas se nutrieron de las mismas fuentes, los retablos del Cono Sur con frecuencia fueron obra de artistas inmigrantes (especialmente de habla alemana), mientras que los del norte fueron hechos en su mayor parte por artesanos criollos. 
Palabras clave: rococó, Trujillo (Perú), retablo, Augsburgo, grabados

\begin{abstract}
The impact of rococo has been traditionally overlooked in the retablos of Peru. Although scholars recognized that rococo appeared on certain retablos of late-18th century Lima and Trujillo as decoration, little effort has been made to investigate how the style reached the viceroyalty. This article identifies printed sources from France and Germany (Augsburg) and considers how artists used them. It also compares the treatment of rococo motifs and forms in Trujillo with the way those forms are treated in the Cono Sur (present-day Argentina and Chile). Although the same sources were used in both areas, the retablos of the Cono Sur were frequently made by immigrants (especially from German-speaking lands) while those in the north were usually made by criollo craftsmen.
\end{abstract}

Keywords: Rococo, Trujillo (Peru), retablos, Augsburg, engravings

LOS HISTORIADORES QUE SE HAN OCUPADO de los retablos hispanoamericanos han tendido a minimizar la importancia del estilo rococó en el tardío siglo XVIII. Aunque es cierto que el estilo quedó en gran medida confinado a la adornación de detalles en los principales centros de producción de retablos en Nueva España y buena parte de América del Sur, el estilo era en cambio muy popular en el Cono Sur en la segunda mitad del siglo -particularmente en los países actuales de Chile y Argentina- como lo muestran varios trabajos recientes (Bailey 2014: 237-96; Bailey y Guzmán 2013: 815-20). Una excepción también importante, aparte de unos pocos retablos producidos en Lima hacia el final del siglo -la serie de Santiago de Surco (antes de 1762) en particular (Figura 3)-, era la ciudad de Trujillo. Desde la época de Ricardo Mariátegui Oliva y Harold Wethey, en la década de 1940, y más recientemente con la obra de Ricardo Estabridis Cárdenas (1991), los estudiosos han reconocido que la serie de retablos realizados después del terremoto de 1759 demues- 
tran una inusual receptividad al estilo francés. Mi propósito en este trabajo no es volver a la historia o patrocinio de estos retablos, sino investigar con precisión cómo estas nuevas influencias europeas llegaron al Perú y de qué forma los artistas en Trujillo las copiaron y transformaron, y así también comparar su impacto en los retablos del Perú con respecto a su recepción en las iglesias contemporáneas del Cono Sur, que utilizaron con frecuencia los mismos modelos. He encontrado que la principal diferencia entre las dos regiones es que, en general, los retablos de la segunda mitad del siglo XVIII en Santiago o Buenos Aires adoptan la estructura casi completa de los modelos europeos-especialmente prototipos para altares rococó impresos en gran número en Augsburgo- mientras que por otra parte los de Trujillo solamente adoptaron parte de la estructura de los modelos germanos, adaptándolas a las formas más típicas del corredor Lima/Trujillo. Sin embargo, los retablos de Trujillo utilizan más decoración de la superficie rococó (al modo francés y alemán) que sus contrapartes en el extenso virreinato del Perú.

Comienzo con una breve consideración acerca de la presencia del arte rococó en el Cono Sur para demostrar qué tipo de modelos llegaron a esas regiones y cómo es que llegaron allí. El rococó alcanzó el Cono Sur a través de cuatro regiones geográficas: desde Francia a través de grabados; de Europa Central a través de artistas, arquitectos, y grabados; y de Portugal y Brasil (donde el rococó tuvo particularmente una gran extensión) a través de los fabricantes itinerantes de muebles y retablos (Bailey 2014: 237, 242-250). ${ }^{1}$ De todos ellos el vínculo germánico fue sin duda el más importante: el sur del continente fue testigo de una importante afluencia de arquitectos, escultores, pintores y artesanos germanos, tal vez la mayor

1 Acerca de los arquitectos y artesanos de España y Portugal en el siglo XVIII en la ciudad de Buenos Aires, ver Arias Incollá (1983: 84-86); Gutiérrez (2010: 2932); Schenone (1982: 237-8); Furlong (1969: 284); Schenone (1955: 40-56). En cuanto a las nuevas y ampliadas iglesias de Buenos Aires de entre 1730 y 1790, también ver Ricardo González (1999: 68). 
emigración de estas características en la historia colonial de América Latina. Casi todos ellos eran hermanos, es decir, coadjutores temporales de la orden jesuita. El rococó también debe su éxito en el Cono Sur a la relativa juventud de sus centros urbanos y a las nuevas fundaciones religiosas en comparación con los centros coloniales más establecidos en el resto de Sudamérica. Una población menor de criollos y mestizos y un mayor número de nuevos inmigrantes de toda la Europa católica -no sólo desde las tierras germánicas, sino también desde Italia y otros lugares-contribuyeron a que las iglesias de la región adquirieran un aspecto más europeo y contemporáneo. Buenos Aires es un buen ejemplo: se convirtió en uno de los epicentros de la decoración rococó durante esa explosión demográfica y la urbanización intensiva en las décadas anteriores a la elevación de la ciudad a capital del nuevo virreinato del Río de la Plata en 1776. Uno de los episodios más notables de esta época fue la reconstrucción de la iglesia jesuita de San Ignacio (1710-1734) -el templo más grande de la ciudad- por los arquitectos alemanes Johannes Kraus, Johannes Wolff, y Peter Weger, junto con los lombardos Giovanni Battista Primoli y Andrea Bianchi (Bailey 2014: 252-257).

En Chile, particularmente, el rococó manifiesta una dependencia directa con los jesuitas alemanes: se cuentan 38 arquitectos, artistas y artesanos entre los 85 misioneros germanos que emigraron a ese país durante el siglo XVIII, más que en ninguna otra región de América Latina (Meier y Müller 2011: VII-IX). Estos jesuitas comenzaron a llegar a finales del siglo XVII, cuando la Corona española relajó la restricción de entrada a los misioneros no españoles y en 1734 todavía una cuarta parte de ellos proviene de tierras de habla alemana (Hanisch 1973: 145). Estos artistas trabajaron en dos talleres principales: la pintura, la escultura y el mobiliario (incluyendo retablos) se hicieron en el Colegio Máximo de Santiago, mientras que los otros oficios se fabricaron en la Calera de Tango, una hacienda al noroeste de la ciudad (Bailey 2014: 250; Cruz y Viñuales 1995: 366; Pereira 1965: 92-94). La más importante de sus comisio- 
nes fue el conjunto de retablos hechos para la iglesia jesuita de San Miguel en Santiago, que fue reconstruida después del terremoto de 1751 y adornada con nuevos retablos en una intensa campaña de construcción de 1748 a 1767.

¿Cuáles fueron los modelos utilizados por estos escultores y arquitectos inmigrantes? Al igual que los retablistas del Perú o Nueva España, los decoradores en Chile y Argentina volvieron a mirar los libros y grabados, pero en vez de buscar modelos flamencos y españoles (que habían prevalecido en América Latina desde el siglo XVI) se volcaron a los diseños franceses y alemanes, específicamente los cuadernos de rocallas, cartelas, trophées, y diseños para retablos y púlpitos impresos en una escala masiva por las editoriales de la calle Saint-Jacques, en París, y en Augsburgo y Múnich (Fuhring 2006: 333-347; Fuhring 1999: 13; Roland Michel 1982: 68; Guilmard 1880: I, 115-249).

Los artistas hispanoamericanos utilizaron distintos modelos alemanes de las estructuras generales de retablos y púlpitos. El escultor Franz Xaver Habermann (1721-1796) fue el diseñador más prolífico de Augsburgo en el ámbito de la decoración eclesiástica: hizo más de 500 grabados entre 1747 y 1770. Fueron publicados en su mayoría por Johann Georg Hertel el Viejo y con ello se volvió el artista más influyente a nivel internacional, debido también a que sus diseños eran relativamente sencillos (Bailey 2014: 120-124; Krull 1977: 11-15, 21-27; Irmscher 2009: 358). Un ejemplo temprano de su influencia en América Latina es el altar de la Virgen de las Nieves en la iglesia de San Ignacio de Buenos Aires (antes de 1767), que es una copia muy cercana de un prototipo de mediados de siglo debido a Habermann y Hertel. Pero motivos decorativos franceses elaborados por Pierre-Edmé Babel, Alexis Peyrotte, René-Jacques Le Charpentier, y Jean-Charles Delafosse han inspirada su ornamentación, otorgando un sabor parisino al interior de las iglesias de Buenos Aires en el último tercio del siglo (Bailey 2014: 252-257; Fuhring 2006: 336-367; Guilmard 1880: 173, 191-192 y 271).Un gran 
desafío en la asignación de los modelos de estos motivos es que, con la excepción de una colección en la Biblioteca Nacional de Río de Janeiro, no sobrevive un solo grabado ornamental rococó impreso en América del Sur. Y, en contraste con los libros (que tienen títulos, portada, tasa, etc.), las hojas sueltas de grabados no se identifican por el nombre ni a veces incluso por el lugar de origen (Bailey 2014: 189). La colección de la Biblioteca Nacional incluye obras sueltas de François Boucher, Antoine Watteau, Christophe Huet, Antoine Coypel, Gabriel Huquier, Marie-Michelle Blondel, Edmé Bouchardon, y François Collignon. Varios de ellos son libros de trofeos, cartelas, jarrones, y chinoiseries. ${ }^{2}$ La evidencia de pintura de los techos de las iglesias brasileñas también demuestra un gran entusiasmo por el trabajo de los grabadores Joseph y Johann-Bautista Klauber de Augsburgo, especialmente los cuadros de santos rodeados de rocallas de lujo (Júnior 2010: 107-130; Ribeiro 2003: 94-97; Guilmard 1880: 443-444). Nada de esto sobrevive en la América española. Por lo tanto, el único recurso es la identificación de los modelos basados en las similitudes estilísticas.

Uno de los mejores retablos supervivientes de Chile es el retablo de San Ignacio (1748-1762), anteriormente situado en el brazo derecho del crucero de la iglesia de San Miguel en Santiago y ahora en la iglesia de San Juan Evangelista en la misma ciudad (Bailey 2014: 268-270; Bailey y Guzmán 2013: 815-820) (Figura 1). Cuenta con un gran nicho central (el cuadro actual es moderno) flanqueado

2 Biblioteca Nacional de Río de Janeiro, E: g: I (Marie-Michelle Blondel, Trophées de couronnes et des casques de fantasie, número 2); E: g: I (Gabriel Huquier, Premier livre de vases inventés par Edmé Bouchardon, sculpteur du Roy, 140 grabados); E: g: II (Gabriel Huquier, Livre de cartouches inventés par François Boucher, 12 grabados); E: g: I (Pierre Aveline, Premier livre de groups d'enfans gravé par Aveline, par F. Boucher peintre du Roy, 6 grabados); E: g: II (Pierre Aveline, «La barque chinoise» Boucher inv.t, un grabado solo); E: g: I (François Collinon. Recueil de douze cartouches, número 4 de series de 12); E: g: I (Pierre Aveline, «Malice de singe», C. Huet inv.); E: g: I (Gabriel Huquier, figuras chinas sin título, 4 grabados); E: g: I, II (Antoine Watteau, escenas varias). 
por alas de columnas; en este caso pares de alas: una contra la pared y la otra alcanzando hacia el frente diagonalmente. Originalmente tenía un banco y un sotabanco (sólo sobrevive el sotabanco), ricamente adornados con cartelas de rocalla. En la parte superior hay una «gloria» rodeada por una corona de volutas compuestas de volutas, rocallas, y guirnaldas. El diseño y adorno del retablo se basa en grabados franceses y alemanes por igual. La corona se toma de un grabado de la iglesia parisina -ya destruida- de Saint-Jean-en-Grève (1720-1721) de Jean-François Blondel, que tiene las mismas volutas yuxtapuestas, una gloria en el centro, y flecos falsos de alfombra encima (Bailey y Guzman 2013: fig. 8; Sécheval 2002: 378; Guilmard 1880: 525). Los cartuchos en el sotabanco formado de pergaminos c, rocalla, gavillas de hierba, y guirnaldas alrededor de un vacío central, son copias cercanas (a veces a la inversa) de diseños en cartela de Habermann de su serie 104 y 111, lo que vamos a ver de nuevo en Trujillo (Figura 2).

Otras características germánicas no se derivan de los grabados, sino más bien de la formación de los artistas en Europa Central. Ellas incluyen columnas estriadas, capiteles y bases de columnas dorados, y particularmente Stuckmarmor, o imitación de mármol pintado, que los trabajos de restauración recientes han descubierto debajo de la pintura moderna (una mezcla de pigmentos rojos, ocres, naranjas, azules y verdes) (Bailey y Guzmán 2013: 818).

$\mathrm{Al}$ igual que en el cono sur, el rococó llegó a Lima a través de láminas decorativas hechas en Augsburgo y París, pero en el área metropolitana del Perú, por el contrario, la influencia de los artistas inmigrantes alemanes era insignificante, a pesar de que algunos alemanes jesuitas estaban activos en la región (Bailey y Guzmán 2013: 815-820; Bailey 2012: 780-785; Wethey 1949: 226). A medida de su importancia, la primera ciudad española de América del Sur, la «Ciudad de los Reyes» desarrolló un estilo distinto de retablo barroco, que en la segunda mitad del siglo XVIII se caracterizó por la altura extraordinaria, características arquitectónicas voluminosas 
(tales como columnas salomónicas, frontones rotos y mixtilíneos, cornisas pesadas), y una decoración saturada, formada de flores apretadas y motivos de fauna. Aunque los elementos ornamentales rococó se añadieron a la mezcla entre los años 1760 y 1790, son meros detalles sobre una estructura que sigue siendo fundamentalmente barroca de estilo hispano. Típico es el altar gigantesco de la Virgen de los Remedios y el Ángel de la Guarda, una vez dorado, en la iglesia de la Merced (1786-1798) en el centro de Lima. Wethey propone que este desarrollo hacia el rococó surgió de la llegada de libros de patrones «franceses» del arquitecto belga de la corte bávara François Cuvilliés (1695-1768) (Wethey 1949: 226). De hecho, los estudiosos de retablos peruanos aún no han considerado la posibilidad de que los modelos alemanes -así como los de Francia- fueran responsables de esta ola de influencia rococó. Aunque ambos tipos de prototipos derivan últimamente del rococó francés, los modelos alemanes eran más prolíficos y más útiles, dado su énfasis en la estructura.

La excepción a la regla limeña, como he discutido recientemente (Bailey 2015: 769-775), es la serie de retablos en la iglesia de Santiago de Surco, que he atribuido a Johann Rehr (Praga, 1691) y Santiago Rosales (antes de 1762). Rehr era un jesuita que ayudó a desarrollar un método de techado resistente a los terremotos que debuta en la catedral después del terremoto de 1746, y que se cree está incorporado en bóvedas de varias iglesias principales de la ciudad como la de San Carlos (ahora Panteón Nacional) y que también construyó, cuando fue destinado allí, una iglesia para la misión jesuítica de San Borja entre los mojos, ahora tierras bajas de Bolivia (1723-1747), antes de su llegada a Lima (Figura 3). ${ }^{3}$ La iglesia de Santiago de Surco, al igual que sus contrapartes en el Cono Sur, adoptó la estructura, así como el diseño de sus prototipos alemanes, método de fabricación de bóvedas, ya que se había practicado en el Perú desde mediados del siglo XVII. Sobre Rehr, ver también Sierra (1944: 260). 
incluyendo no sólo las creaciones de Habermann, sino igualmente los más extravagantes diseños para retablos, confesionarios y púlpitos, producidos por artistas como Ignaz Carl Junck, Emanuel Eichel y Jeremias Wachsmuth (Figura 4).

Trujillo estuvo estilísticamente más profundamente vinculado a Lima que el resto de las ciudades del Perú y allí también comenzaron a producir retablos con motivos rococó en algún momento entre 1760 y 1763. Por lo general, se trata de altares laterales y púlpitos -algunos de ellos muy delicados, a diferencia de los retablos monumentales de Lima- comenzando con el retablo del Niño Jesús de Praga en la iglesia del Carmen (Figura 5). Sin embargo, la descripción de la mayoría de estos retablos nunca ha sido publicada, por lo mismo que los estudiosos se han centrado principalmente en los períodos anteriores y en el barroco. Mariátegui sugiere que el rococó hizo acto de presencia en Trujillo a través de la influencia francesa, a pesar de que en ningún momento hizo comparaciones directas con grabados u otras fuentes franceses para fundamentar su aseveración: «la influencia francesa [...] se presenta como estilo de transición y puro, tanto del denominado Luis XIV, como del rococó Luis XV, señalado la lucha tenaz por conservarse estas formas ondulantes, que tanto se conformaron al espíritu y al sentir de tan gentiles pobladores, para terminar con la reacción clasicista» (Mariátegui 1946: 61; Estabridis 1991: 157). Según Mariátegui, el estilo llegó a Perú durante el reinado de Felipe V (1700-1743) y del virrey don Manuel de Amat y Juniet (1761-1776), cuando un acuerdo comercial con Francia dio lugar a la «invasión del estilo» (Mariátegui 1946: 36). Este curioso uso de lenguaje militar cuando se describe la llegada de la influencia francesa en el Perú se repite en la obra de Wethey: «El rococó francés tomó la escena con una demostración de fuerza que pronto sonaría el toque de difuntos del barroco hispano» (Wethey 1949: 226).

Los retablos de Trujillo son en la mayor parte relativamente planos, en comparación con los de Lima, aunque todavía tienen en- 
tablamentos y frontones rotos que arrojan luz sobre las superficies con un dramático claroscuro. Tienden a ser de dos plantas de altura con un piso superior más corto y los nichos centrales más anchos y prominentes, a veces proyectándose hacia el frente: en algunos casos la calle central se mueve hacia delante de manera que los lados se forman en una diagonal (Figura 5). En general, la decoración se extiende libremente sobre la superficie usando patrones repetidos, lo que da un efecto mucho más ligero que los retablos densamente decorados de Lima y eso también contribuye a la calidad llana y ligera en general del retablo. En la mayor parte, el dorado se emplea sólo en detalles como molduras, rocallas, conchas estilizadas, follaje y otros detalles ornamentales. En lugar de columnas salomónicas, estos retablos tienden a utilizar estípites (columnas segmentadas, a veces formada por rocallas), con cabezas o torsos humanos: las figuras de busto-cariátides en las que Wethey en particular se mostraba muy interesado, así como las formas bulbosas que también aparecen en Surco (Figura 3). ${ }^{4}$

Algunos retablos están coronados con una forma de escudo distintivo que también era común en Brasil, sobre todo en Río de Janeiro (Ribeiro 2010: 142). La más señalada colección de retablos rococó se encuentra en la iglesia del Carmen (Figura 5) y en la catedral (Figuras 9 a 13) y hay un retablo notable inédito también en la iglesia de Santa Clara (Figura 14).

El retablo y el púlpito rococós del templo del monasterio del Carmen (Figuras 5 y 6) no tienen fechas, pero se concluyó la reedificación de la iglesia después del terremoto de 1763 y Mariátegui cree que son las obras rococó más antiguas de todo Trujillo (Estrabridis 1991: 157-158; Wethey 1949: 227; Mariátegui 1946: 71; Mariátegui 1945: 4-8). El retablo estuvo dedicado anteriormente al Niño Jesús de Praga y ahora a San Juan Bautista; es uno de los mejores reta-

4 En cuanto a la cariátide de busto sin brazos que estaba en la cúspide de su popularidad en los años 1760 y 1770, consultar Wethey (1949: 227-237) y Estabridis Cárdenas (1991: 157-158). 
blos rococó de la ciudad (Figura 5). Cuenta con una red delicada y elegante de decoración que se extiende sobre una estructura de dos cuerpos y una sola calle con ocho columnas estípites formadas de rocallas, mientras las cuatro internas presentan cariátides de busto sin brazos. De particular delicadeza son las cartelas asimétricas entre los pares de columnas exteriores en ambos niveles. A diferencia de los otros retablos rococós en Trujillo, este sigue siendo totalmente dorado, produciendo un efecto brillante y resplandeciente. El retablo está coronado por un escudo rococó típico formado de follaje y volutas que contiene un Sagrado Corazón de Jesús. A pesar de que el retablo tiene sólo una calle, las secciones que la flanquean le dan una estructura tripartita.

Al igual que los retablos del Cono Sur y de Santiago de Surco, el retablo del Carmen usa modelos franceses y alemanes. De hecho, utiliza los mismos modelos. Los escudos entre el par exterior de columnas son versiones alargadas de un modelo de cartucho de Pierre-Edmé Babel (mediados del siglo XVIII), que fue ampliamente replicado en los retablos de Buenos Aires y Santiago, en particular, en el frontal del altar en la catedral de Buenos Aires, ejecutado por Isidro Lorea (1774-1784) (Bailey 2012: 781-785). Sin embargo, en el retablo bonaerense el cartucho se copia en cierta manera fielmente mientras que, en El Carmen, los cartuchos se extienden hacia fuera de manera que los elementos de rocalla son más prominentes y todo el escudo parece segmentado. El escultor también ha añadido una cabeza humana, una pequeña versión de una de las cabezas de cariátides, en el medio de los dos cartuchos inferiores (del primer cuerpo), lo que refleja el gusto limeño. Cada cuerpo se basa en el mismo grabado de Augsburgo, una vez más utilizado en Santiago de Surco: un prototipo de un altar de la serie 78 diseñado por Eichel y Hertel (Figura 4). El modelo tiene un par de cabezas de cariátides sobre columnas segmentadas formadas de rocallas y un par externo de columnas, similarmente segmentado y adornado con rocallas, que están a su vez coronadas con capiteles corintios. Ambos (el 
modelo y el retablo) también tienen una calle central que se proyecta hacia adelante, de modo que las calles que flanquean se colocan en una diagonal. Aquí el retablo está suficientemente cerca de los dos modelos -los detalles de las columnas y rocallas y pergaminos se aproximan mucho a ambos originales- que el artista pudo haber utilizado; sin embargo, reemplazó las cabezas de cariátides con las cariátides de busto que ya se habían convertido en parte del vocabulario habitual de los retablistas limeños y trujillanos. Aunque es más corto, el segundo cuerpo repite la estructura y los elementos de la inferior (pero sin las cabecitas).

Al costado de la nave central, ante el retablo del Niño Jesús de Praga, está el púlpito, decorado en el mismo estilo rococó y dorado de manera similar (Figura 6). Se accede al púlpito desde una escalera a través de la pared. No cuenta con escalera adosada, lo que era normal en púlpitos de esta época. Me parece que el púlpito actual es resultado de combinar dos púlpitos diferentes: el tornavoz y respaldo provienen de un estilo barroco más tradicional y la tribuna y el apoyo al muro responden al estilo rococó, lo que sugiere que las partes superiores habían sobrevivido al terremoto o por lo menos tuvieron otro artista diferente (Estrabidis Cárdenas 1991: 157-158). La tribuna y el apoyo se inspiran de nuevo en la cartela Babel, pero su tratamiento es más cercano al original, dado que los cartuchos no son alargados como los del retablo y circulan a través del púlpito (Figura 7). Las rocallas más opulentas y volumétricas se encuentran en el apoyo, dividido en paneles por apéndices curvilíneos en forma de lóbulo; particularmente cercana al diseño original es la forma en que las rocallas se retuercen, dando al relieve de la superficie una calidad más volumétrica. El apoyo en la parte inferior es particularmente robusto, con una agregación de rocallas pesadas, torciéndose liberalmente, que son adaptadas de la obra de Babel. En los paneles alrededor de la tribuna hay marcos más sencillos que también recuerdan otros prototipos de Babel, esta vez una serie de marcos vacíos sin fecha, cada uno titulado Cartouche Nouveau (Figura 
8). Mariátegui cree que el púlpito de la iglesia del Carmen es tan original que fue producido por un solo escultor: «constituye [...] una obra única en Trujillo, desde el punto de vista estilístico, por su exacta conformación y proporciones, dando la impresión, también, de no tratarse de labor de ensamblaje, sino de refinada orfebrería» (Mariátegui 1946: 78). También son estas dos obras, probablemente, los únicos ejemplos de rococó en Trujillo que todavía se refieren a modelos originales grabados.

Con respecto a los cuatro retablos rococó de la catedral -de Santo Toribio (1790), de la Virgen del Perpetuo Socorro (ahora Sagrado Corazón de Jesús), San José y el Cristo Crucificado de las Ánimas- es evidente que los retablistas han reducido radicalmente la cantidad de dorado, relegándolo sólo a los detalles decorativos (Figuras 9-12). Por lo menos el altar de Santo Toribio se encargó a los retablistas Diego Fernández Briseño (responsable de los bultos, incluyendo el de Santo Toribio) y Juan Inocencio de Heredia (supuestamente ensamblador y dorador). Así lo dispuso en 1790 el obispo Baltasar Jaime Martínez Compañón, que permaneció en Trujillo desde 1779 hasta ese año de 1790. Los otros tres retablos pueden ser atribuidos estilísticamente a los mismos autores (Mariátegui 1946: 50, 70-71; Gutiérrez 1984: 128). Los cuatro retablos hacen uso de una ornamentación parecida, con rocallas, volutas y follaje, y emplean el mismo tipo de columna estípite con cariátides de busto; sin embargo, estas no aparecen en los mismos lugares en todos los retablos. Los retablos de la Virgen del Perpetuo Socorro y San José (Figuras 10 y 11) son tan similares que Mariátegui los llama «gemelos» (Mariátegui 1946: 71). Los retablos más amplios -todos excepto Santo Toribio tienen tres calles- muestran cuatro columnas en cada cuerpo. En los retablos gemelos, las cariátides de busto se ubican en el cuerpo inferior mientras que en el cuerpo superior solamente el par central de columnas tienen cariátides y los exteriores tienen capiteles corintios. El retablo de Cristo Crucificado de las Ánimas es un poco más complicado, con cuatro columnas en el 
cuerpo inferior (el par central con bustos de cariátides), pero tiene también dos pilastras estípites en el gran nicho del centro; el parte superior es parecida, con cuatro pequeñas columnas flanqueando el nicho central (ninguna con cariátides) y dos pilastras en el nicho. Los de Santo Toribio y los gemelos no tienen estas pilastras dentro de sus nichos: solamente cuentan con un marco rococó alrededor del nicho central del cuerpo inferior.

Los cuatro retablos del catedral parecen basarse, una vez más, en el modelo de Eichel, pero en este caso probablemente de segunda mano, inspirados por el retablo en el Carmen (Figuras 4 y 5). Es posible que, como parte de la práctica normal de taller, los escultores realizaron cuadernos con diseños que citaban partes de otros retablos y también interpretaban copias que escultores anteriores habían hecho de grabados franceses, sin necesidad de tener acceso a los grabados originales. Si bien son de diferentes anchuras, los cuatro retablos de la catedral son más planos que el del Carmen de modo que el ornamento luce más desplegado y tiene un efecto más ligero, lo que se ve reforzado por la falta de dorado, una característica que también se aplica a los retablos de Surco (Figura 3). Particularmente en los retablos gemelos, la escultura es muy delicada, especialmente el acabado de conchas que en los dos frontones adquiere una cualidad tridimensional muy similar a los estucos alemanes (Figuras 10 y 11). Las rocallas son particularmente buenas, con ondas y bordes fuertemente biselados, lo que también aumenta su volumen y les da una considerable vivacidad. Los dos retablos cuentan con cartuchos en el sotabanco formados de rocallas alrededor de un vacío central que usan el mismo modelo de Augsburgo (Habermann y Hertel, series 104 y 111). Ocurre igual en el retablo de San Ignacio en Santiago de Chile, aunque los retablistas de la catedral se copian menos exactamente del diseño y parece otra vez que se han hecho a partir de unos bocetos de segunda mano (Figuras 2 y 13).

El retablo de Santo Toribio (Figura 9), el único que presenta nichos solo en la calle central, es más cercano al del Carmen (Figu- 
ra 5), manteniendo el perfil alto y estrecho del retablo anterior y por esta razón es probable que fuera la primera manifestación rococó construida en la catedral. Sin embargo, invierte la relación entre la sección central y las dos calles exteriores en el cuerpo principal, con el nicho de retroceso hacia el interior en lugar de sobresalir hacia fuera, con un efecto de relieve por los paneles estrechos entre las columnas que provocan un movimiento diagonal hacia adentro. Las columnas también se invierten: el par de columnas cariátides en el exterior y de las delgadas columnas corintias en el interior. Esta inversión da un carácter lúdico al retablo cuando se considera junto con su probable modelo.

El retablo de San Antonio de Padua en la iglesia de Santa Clara, el mismo que ignoran Wethey, Mariátegui y Estabridis, es en mi opinión uno de los retablos rococó más elegantes en la ciudad (Figura 14). Consiste en una sola calle con dos cuerpos, como los altares del Niño Jesús en el Carmen y el altar de Santo Toribio en la catedral, y cuenta con una rica ornamentación dorada de rollos y rocallas. También es mucho más policromada que los otros retablos. El cuerpo principal cuenta con un solo par de columnas estípites en el exterior con cabezas cariátides (los bustos son poco más que corazas), mientras que las columnas interiores se han reducido a rollos. El cuerpo superior tiene cuatro pequeñas columnas formadas también de rocallas y los dos exteriores con cabezas de cariátides. Las cabezas de cariátides se repiten en una escala aún más pequeña en el sotabanco en pequeñas columnillas de rocallas entre los paneles de rocalla como los del púlpito en el Carmen. Aunque no hay forma de saber si la pintura es original, este retablo también es único en el uso de Stuckmarmor en las alas de ambos cuerpos y también cuenta con pinturas en colores brillantes de ramos de flores de rosa sobre un fondo blanco - este fondo, de hecho, se asemeja a marfil- en los paneles que flanquean el nicho principal en el cuerpo principal. Ciertos detalles decorativos, especialmente las columnas cariátides y la red de ornamentación en los frontones del primer 
cuerpo, son suficientemente similares al tallado de los cuatro retablos de la catedral como para atribuir este retablo al mismo equipo de Briseño y Heredia y así podríamos darles una fecha de ca. 1790.

Lo fascinante de la manera en que los decoradores de Trujillo (y sus contrapartes en el Cono Sur) utilizan estos grabados franceses y alemanes es que rara vez han copiado motivos enteros, para elaborar, en lugar de reproducir, pastiches de grabados diversos o -más frecuentemente- transformarlos por medio de sus propias invenciones, utilizándolos más bien para provocar su libre inspiración. ${ }^{5}$ Este método es contrario a la práctica tradicional en la América española en la que los artistas copian la mayor parte de la imagen y luego agregan nuevos elementos como flora y fauna de su región, referencias a la cultura indígena o simplemente diferentes colores o detalles decorativos originales. ${ }^{6}$ Este enfoque refleja la forma inusual en que los grabados decorativos rococó fueron destinados a ser utilizados: raramente se diseñaron con una función, significado o medio particular; muy pocos de ellos fueron derivados de edificios u objetos existentes y los artesanos también en Europa podrían aplicar la misma rocalla a un panel de pared o a una tetera. A menudo eran cartuchos de fantasía, ubicados en paisajes de Arcadia o distribuidos al azar a través de la página y los artesanos llegaron incluso a animar a sus clientes a desmantelar y reorganizar los motivos individuales con tijeras. ${ }^{7}$ Patrones rococós disfrutaron de una

5 En consecuencia, es extremadamente difícil rastrear motivos individuales en sus modelos, algo que Hermann Bauer ha observado respecto del estuco rococó alemán (1962: 40-47). Ver también Harries (1983: 18).

6 Hay una extensa literatura científica referida a la reproducción de grabados en la América Latina colonial. Una bibliografía selectiva de publicaciones recientes debería incluir a Fajardo de Rueda (2011); Bargellini (2010); Vives Mejía (2010); García Sáiz (1996 y 1999); Gutiérrez (1995); Alcalá (1993); Báez Macías (1982).

7 Los lectores se animaban incluso a diseccionar y deformar grabados decorativos, y esto ocurrió así literalmente, durante una moda en la década de 1720 y 1730, para recortar con tijeras las rocallas y pegarlas en álbumes o -como en el Nouveau livre de principes d'ornemens (ca. 1750) con diseños de Claude Gillot 
cálida recepción internacional, desde Alemania hasta la Patagonia, precisamente porque sus interminables permutaciones y metamorfosis desalientan la imitación servil y permitieron a los artistas disfrutar de su propia creatividad, haciendo invenciones a veces muy diferentes de las de la calle Saint-Jacques o de los impresores de Augsburgo.

Trujillo tiene una de las colecciones de retablos más importantes de finales del siglo XVIII en Perú, que destacan por la variedad y originalidad de sus diseños y la sutileza de su ornamentación. Aunque tenían estrechos lazos estilísticos con los grandes talleres de retablo de Lima, los retablistas de Trujillo son mucho más que sólo un reflejo provincial de la metrópoli. Una de las características más singulares de los retablos realizados en Trujillo fue su entusiasmo por los diseños más recientes de Francia y Alemania y su relación con el rococó internacional. A pesar de que estos patrones no transformaron completamente las formas ibéricas antiguas, les dieron un acento delicado que era muy diferente del diseño retablo tradicional en Perú y más parecido a los retablos construidos en el Cono Sur, especialmente Santiago y Buenos Aires y reflejaron un gusto nuevo en gran parte de la América española por interiores más ligeros y menos ornamentados.

(1673-1722)- copiarlas usando un espejo que se vende con el libro. Ver Roland Michel (1984: 69); Laing (1983: 113-115). Eichel produjo una serie de grabados con nada menos que 15 rocallas por hoja; por ejemplo, en la École Nationale Supérieuredes Beaux-Arts, París (ENSBA), Est. Les. 24, ff. 68-70. 


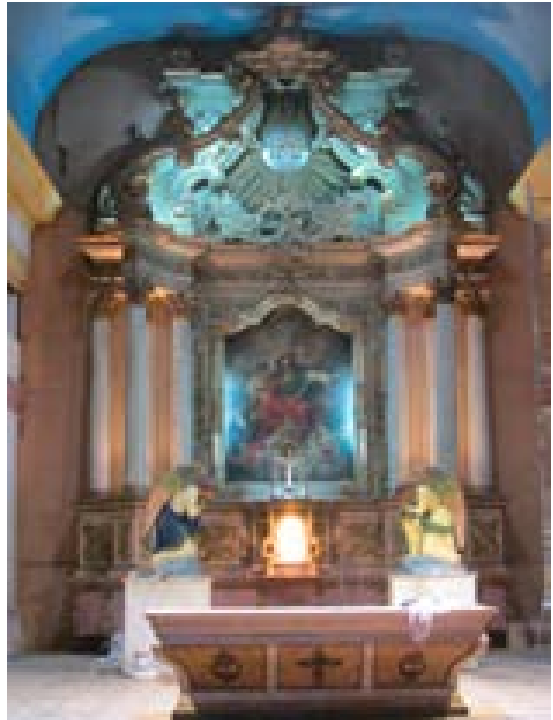

Figura 1

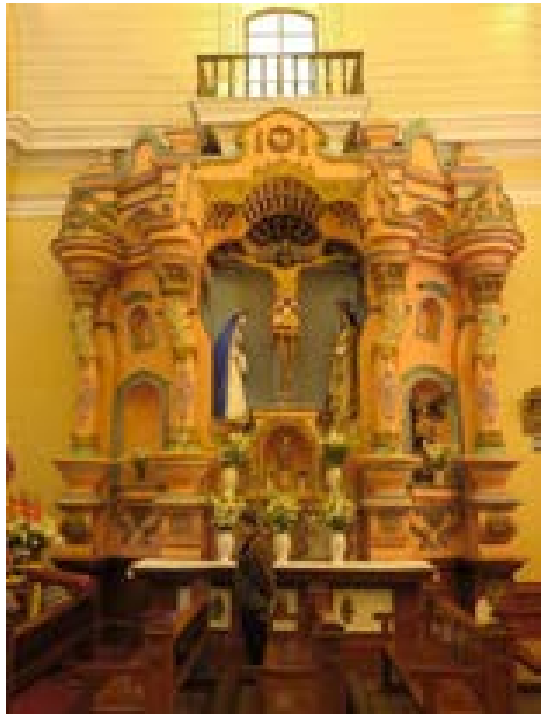

Figura 3

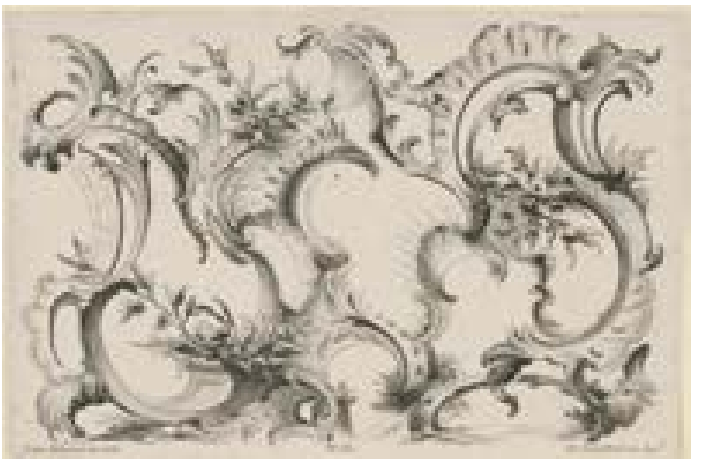

Figura 2 
Grabados decorativos europeos y los retablos rococó del siglo XVIII en Trujillo (Perú)

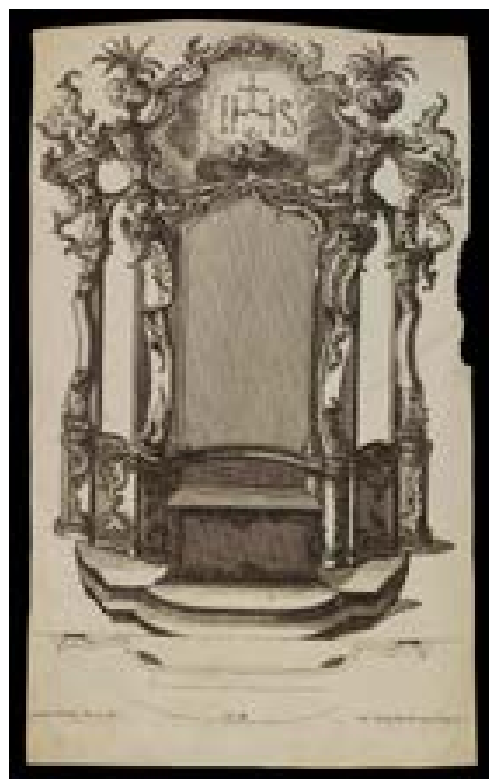

Figura 4

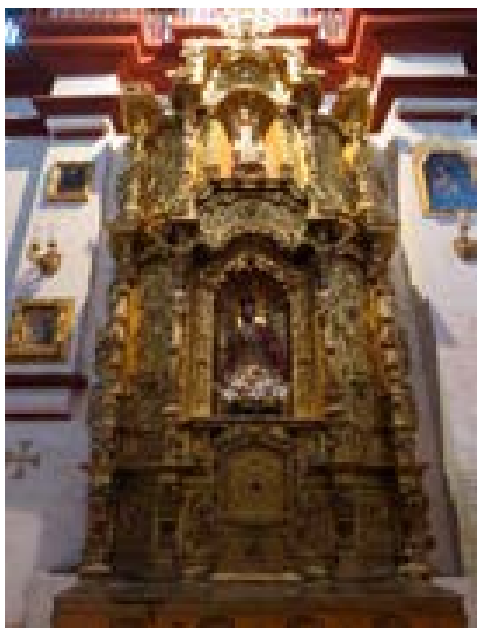

Figura 5

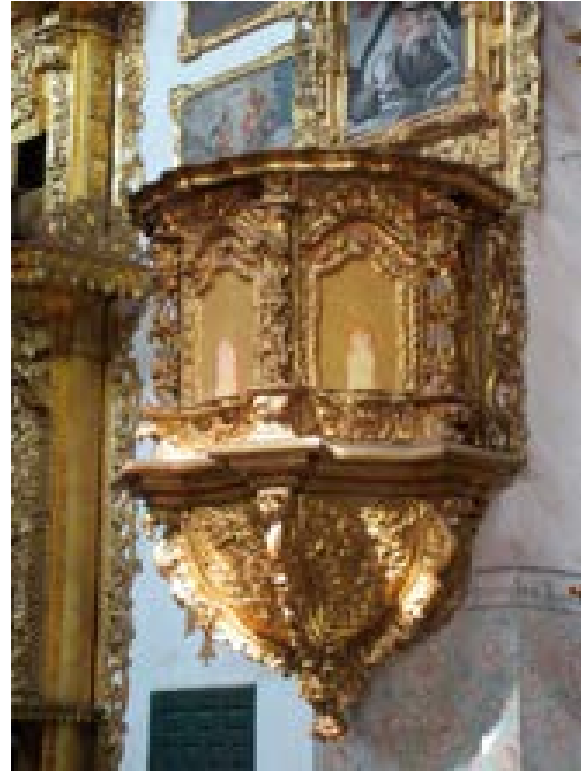

Figura 6 


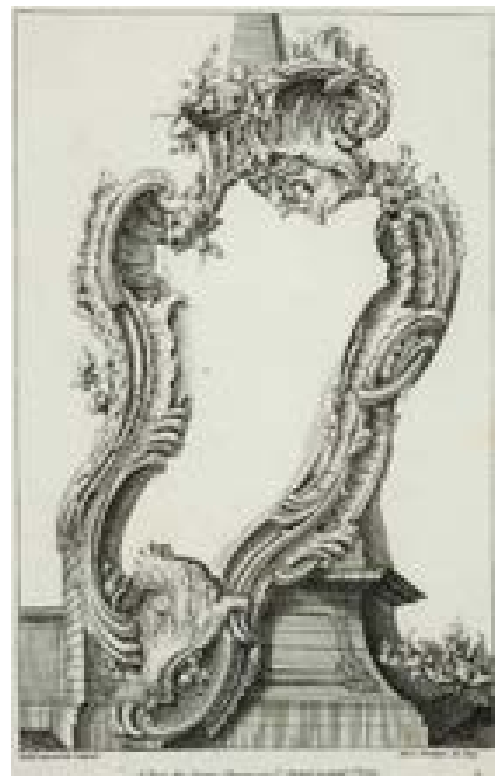

Figura 7

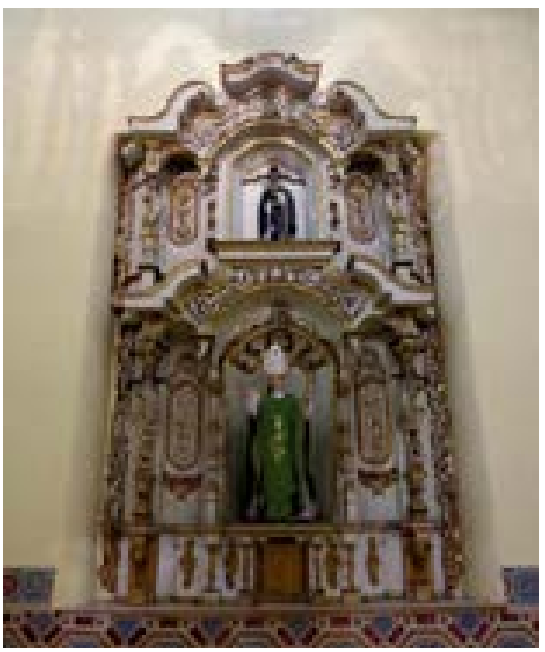

Figura 9

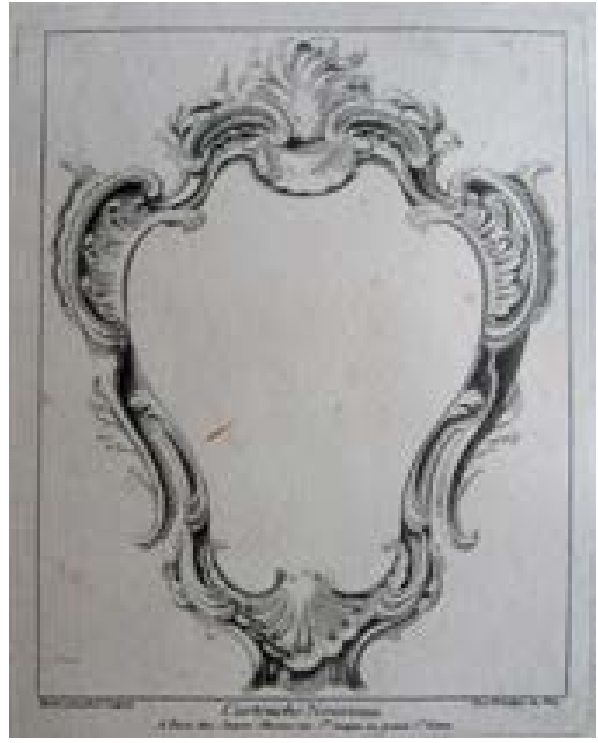

Figura 8 
Grabados decorativos europeos y los retablos rococó del siglo XVIII en Trujlllo (Perú)

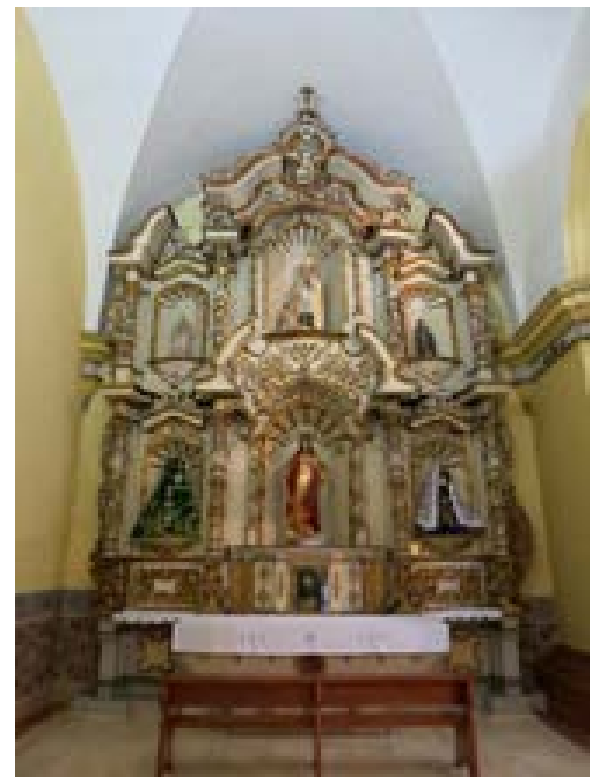

Figura 10
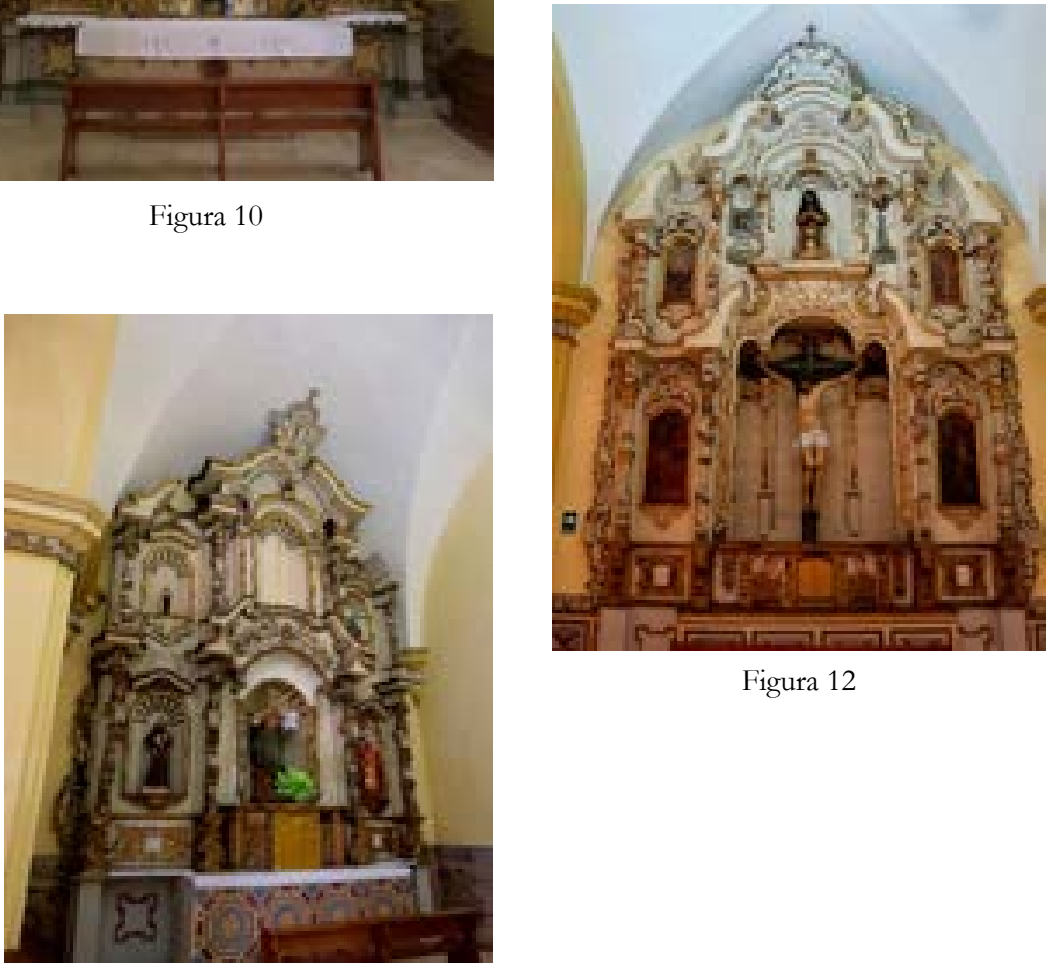

Figura 12

Figura 11 
Gauvin Alexander Bailey

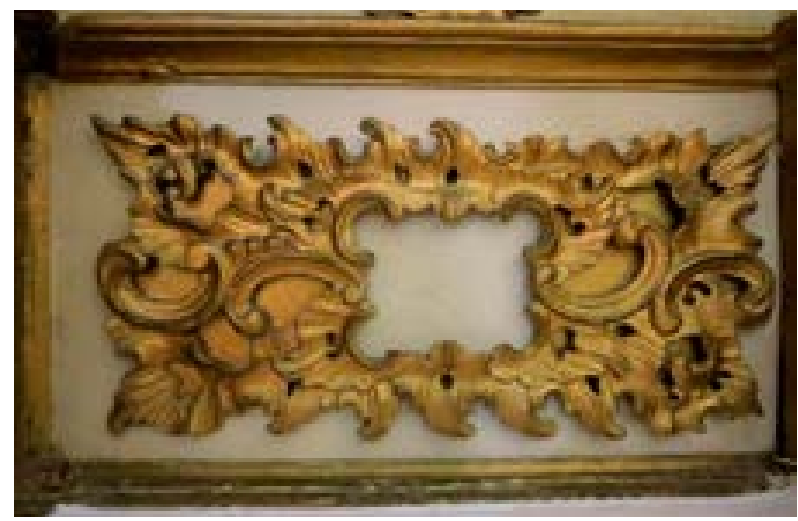

Figura 13

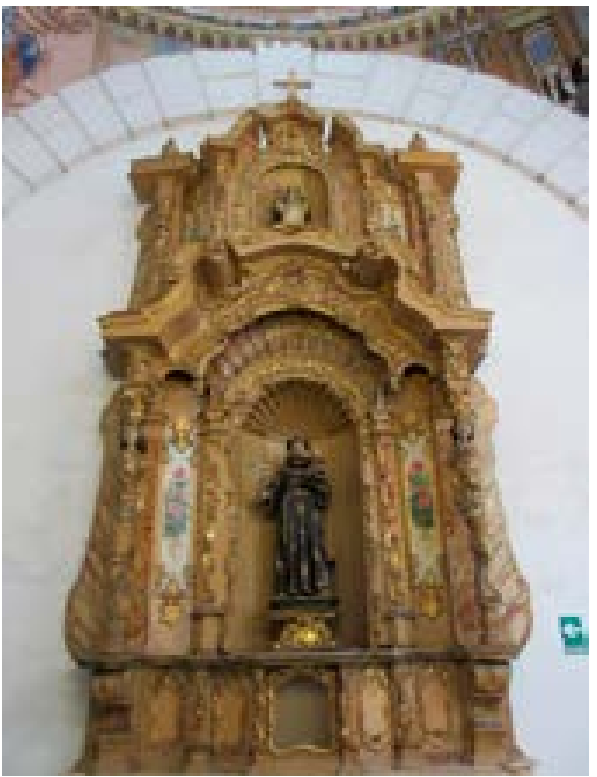

Figura 14 


\section{REFERENCIAS}

AlCALÁ, L. E.

1993 «Las imágenes de Jerónimo Nadal y un retablo novohispano». Anales del Instituto de Investigaciones Estéticas, vol. XVI/64, pp. 47-55.

Arias Incollá, María de las Nieves

1983 «Evolución arquitectónica». En: María I. Soulés, et al. (eds.). Manzana de las Luces Iglesia de San Ignacio XVII-XX. Buenos Aires: Instituto de Investigaciones Históricas de la Manzana de las Luces Dr. Jorge E. Garrido, pp. 84-86.

BÁEz Macías, E.

1982 «El grabado durante la época colonial». En J. Salvat y J. L. Rosas (eds.). Historia del Arte Mexicano, tomo VI. México: Salvat Mexicana de Ediciones.

BAILEY, Gauvin Alexander

2012 «French Rococo Prints and Eighteenth-Century Altarpieces in Buenos Aires». The Burlington Magazine, vol. CLIV, n. 1316, pp. 780-785.

2014 The Spiritual Rococo: Decor and Divinity from the Salons of Paris to the Missions of Patagonia. Farnham: Ashgate.

2015 «The Fantastical Rococo Altarpieces of Santiago de Surco, Peru». The Burlington Magazine, vol. CLVII, n. 1352, pp. 769-775.

BAILEY, Gauvin Alexander y Fernando Guzmán

2013 «The Rococo Altarpiece of Saint Ignatius: Chile’s Grandest Colonial Retable Rediscovered». The Burlington Magazine, vol. CLXV, pp. $815-820$.

Bargellini, C.

2010 «Difusión de modelos: grabados y pinturas flamencos e italianos en territorios americanos». En: J. Gutiérrez Haces (ed.). Pintura de los Reinos: Identidades Compartidas. Territorios del Mundo Hispánico, siglos XVI-XVIII. Ciudad de México: Fomento Cultural Banamex, pp. 964-1007. 
BAUER, H.

1962 Rocaille. Zur Herkunft und zum Wesen eines Ornament-motivs. Berlín: Walter de Gruyter.

Castelli, A.

1996 «La importancia de la imprenta Plantin para la América Colonial». Histórica, vol. XX/2, pp. 313-322.

Cruz De Amenábar, Isabel y Graciela M. Viñuales

1995 «La pintura en Chile y en el virreinato del Río de La Plata». En: Ramón Gutiérrez (ed.). Pintura, Escultura y Artes Útiles en Iberoamérica, 1500-1825. Madrid: Manuales Arte Cátedra, pp. 177-188.

Estabridis CÁrdenas, Ricardo

1991 «La escultura en Trujillo». En: José Antonio de Lavalle (ed.). Escultura en el Perú. Lima: Banco del Crédito del Perú, pp. 157-58.

Fajardo de Rueda, M.

2011 «Del grabado europeo a la pintura americana». Historelo, vol. 3, n. 5, pp. 191-214.

FuHRING, Peter

1999 Juste-Aurèle Meissonnier: un génie du Rococo. Turín; Londres: Umberto Allemandi.

2006 Designing the Décor: French Drawings from the Eighteenth Century. Lisboa: Fundação Gulbenkian.

FURLONG, Guillermo

1969 Historia social y cultural del Río de la Plata (1536-1810). El transplante cultural: arte. Buenos Aires: Tipográfica Editora Argentina.

García SÁiz, M. C.

1999 «La interpretación de los modelos europeos en las artes de tradición indígena». En: A. Bustamante García et al. (eds.). Felipe II y el arte de su Tiempo. Madrid: Fundación Argentaria, pp. 293-303. 
GuILMARD, Désiré

1880 Les maîtres ornemanistes: dessinateurs, peintures, architectes, sculpteurs et graveurs: Écoles français, italienne, allemande et des Pays-Bas. París: E. Plon.

GONZÁLEZ, Ricardo

1999 «El culto público». En: Ricardo González et al. Arte, culto e ideas: Buenos Aires, Siglo XVIII. Buenos Aires: Fundación para la Investigación del Arte Argentino.

GutiérREZ, Ramón

1995 «Los circuitos de la obra de arte. Artistas, mecenas, comitentes, usuarios, y comerciantes». En: R. Gutiérrez (ed.), Pintura, Escultura, y Artes Útiles en Iberoamérica, 1500-1825. Madrid: Manuales Arte Cátedra.

GutiÉRrez, Ramón (ed.)

2010 Alemanes en la arquitectura argentina. Buenos Aires: Ministerio de Relaciones Exteriores y Culto.

GutiérRez, Ramón, Rodolfo Vallin y Mireya Muñoz

1984 «Los seminarios del Obispo Martínez Compañón en el norte peruano». Histórica, vol. VIII, n. 2, pp. 111-129.

Hanisch Espíndola, Walter

1973 «El P Carlos Haimbhausen SJ precursor de la industria chilena». Jahrbuch für Kunstgeschichte von Staat, Wirtschaft und Gesellschaft Lateinamerikas, n. 10, pp. 133-206.

HARries, K.

1983 The Bavarian Rococo Church: Between Faith and Aestheticism. New Haven y Londres: Yale University Press.

Hurtado Valdez, P. A.

2011 Bóvedas encamonadas: origen, evolución, geometría y construcción entre los siglos xvii y xviii en el virreinato de Perú. Tesis de doctorado. Madrid: Universidad Politécnica de Madrid. 
IRMSCHER, Günther

2009 «Style rocaille». Barockberichte, n. 51-52, pp. 339-414.

JúNIOR, Rubem Amaral

2010 «Emblematica Mariana no Convento de São Francisco de Salvador, Bahia, e seus modelos europeus». Lunem et Virtus, vol. 1, n. 3, pp. 107-130.

KRULL, Ebba

1977 Franz Xaver Habermann (1721-1796): ein Augsburger Ornamentist des Rokoko. Augsburgo: Hieronymus Mühlberger.

Mariátegui Oliva, Ricardo

1945 Una iglesia-relicario, el Carmen de Trujillo. Lima: Instituto de Investigaciones de Arte Peruano y Americano.

1946 Escultura colonial de Trujillo: estatuas, relieves, retablos, pulpitos. Lima: Alma Mater.

MeIER, Johannes, y Michael Müller

2011 Jesuiten aus Zentraleuropa in Portugiesisch-und Spanisch-Amerika 2. Chile y Münster: Aschendorff.

Pereira Salas, Eugenio

1965 Historia del arte en el reino de Chile. Santiago: Universidad de Chile.

Roland Michel, Marianne

1982 «L'ornement rocaille: quelques questions». Revue de l'Art, n. 55, pp. 66-75.

Ribeiro de Oliveira, Myriam Andrade

2003 O rococó religioso no Brasil e seus antecedentes europeus. São Paulo: Cosac y Naify.

SÉcheval, Anne Le Pas de

2002 «Entre hommage et trahison: la réception et l'adaptation du baldaquin de Saint-Pierre». En: C. Grell et M. Stanic (eds.). Le Bernin et l'Europe, actes du colloque de 1998. París: Presses de l'Université de Paris-Sorbonne, pp. 375-90. 
Sierra, Vicente

1944 Los jesuitas germanos en la conquista spiritual de Hispano-América. Buenos Aires: Padilla y Contreras.

Vives Mejía, G. A.

2010 «El arte colonial y los grabados». Desde la Sala, n. 16, pp. 58-60.

WETHEY, Harold

1949 Colonial Architecture and Sculpture in Peru. Cambridge: Harvard University Press. 